\title{
Chapter 2 \\ Evolution of Saline Lakes \\ in the Guanzhong Basin During the Past 2000 Years: Inferred from Historical Records
}

\author{
Jie Fei, Hongming He, Liang Emlyn Yang, Xiaoqiang Li, Shuai Yang \\ and Jie Zhou
}

\begin{abstract}
This study reconstructed the possible existence of saline lakes in the Guanzhong Basin during the past 2000 years. Using Chinese historical literature as well as stone inscriptions, a total of five historical saline lake bodies which had existed in this region were documented: Lakes Yanchize, Xiluchi, Dongluchi, Zhuyanze and Xiaoyanchi. Lakes Zhuyanze, Yanchize, Xiluchi, Dongluchi, and Xiaoyanchi desiccated respectively at some point during 1076-1701 AD, 1584-1735 AD, 1666-1791 AD, 1666-1791 AD, and 1712-1906 AD. The lakes in the west of this region possibly desiccated relatively early, and the lakes in the east desiccated relatively late. Most of the lakes desiccated during a cold climate period. It seems that the dry period of the 15th-17th centuries overlapped with the periods that some of the lakes desiccated. All the five lakes desiccated during periods of increased soil erosion. The main causes of the degradation and desiccation of Lakes Yanchize, Xiluchi and Dongluchi were flood irrigation and silt sedimentation. The degradation and desiccation of Lake Yanchize and Lakes Dongluchi and Xiluchi corresponded to periods of population explosion when land was heavily cultivated in Fuping and Pucheng Counties. The existence of historical saline lakes indicates that the remains of the Sanmen Paleo-Lake existed in the Guanzhong Basin during the past 2000 years.
\end{abstract}

\footnotetext{
J. Fei $(\varangle) \cdot$ S. Yang

Institute of Chinese Historical Geography, Fudan University, Shanghai 200433, China

e-mail: jiefei@fudan.edu.cn

H. He · J. Zhou

Institute of Soil and Water Conservation, Chinese Academy of Sciences, Northwest A\&F

University, Yangling Shaanxi 712100, China
}

\section{E. Yang}

Graduate School Human Development in Landscapes, Christian-Albrechts-Universität zu Kiel, Leibnizstraße 3, 24118 Kiel, Germany

\section{Li}

Institute of Vertebrate Paleontology and Paleoanthropology, Chinese Academy of Sciences, Beijing 100044, China

L. E. Yang et al. (eds.), Socio-Environmental Dynamics along the Historical Silk Road, https://doi.org/10.1007/978-3-030-00728-7_2 
Keywords Desiccation $\cdot$ Population density $\cdot$ Cultivated land ratio Flood irrigation $\cdot$ Silt sedimentation

\subsection{Introduction}

Analysis of the evolution, degradation and desiccation of saline lakes during the past 2000 years will help us to better understand the geographical distribution and evolution of saline lakes. There are more than 1500 modern saline lakes in China (Zheng et al. 1993). Knowledge of the historical saline lakes is not as advanced as geographical and historical value suggests it should be, since historical saline lakes contain information about local hydrology, regional environmental change and salt resources.

No saline lakes exist in the Guanzhong Basin in modern times (Williams 1991; Zheng et al. 1993; Wang and Dou 1998; Zheng et al. 2002). Here, the possible existence of historical saline lakes in this region during the past 2000 years is examined. We deduce the dates of their desiccation, and discuss the relationship with environmental change and human activity.

\subsection{Regional Setting}

The Guanzhong Basin lies in the middle Shaanxi Province, China, and sometimes it is also referred to as the Weihe River Plain (Fig. 2.1). The Weihe River is the largest tributary of the Yellow River. The total length of the river is $818 \mathrm{~km}$, and it flows through the Guanzhong Basin from west to east. However, the Weihe River Plain does not correspond exactly to the Guanzhong Basin because there are several patches of undrained depressions in the basin, and these depressions are exactly where saline lakes could exist.

This region is well known as a major cradle of ancient Chinese civilization. Xi' an and its vicinity formed the national capital city of China during the Western Zhou Dynasty (1046-771 BC), Qin Dynasty (221-206 BC), Western Han Dynasty (206 BC-25 AD), Sui Dynasty (581-618 AD) and Tang Dynasty (618-907 AD). This region is tectonically a graben basin between the Loess Plateau and Qinling Mountain. The basin extends about $400 \mathrm{~km}$ from west to east, and about $30-80 \mathrm{~km}$ from south to north. It occupies an area of $19,000 \mathrm{~km}^{2}$, and the altitude is $325-900 \mathrm{~m}$ above sea level.

The climate in the region is mostly a semi-arid temperate East Asian monsoon type, with a few patches of sub-humid type in the southwest part. The annual mean temperature is $11-14{ }^{\circ} \mathrm{C}$, and the monthly mean temperatures of January and July are -2 to -1 and 25 to $27{ }^{\circ} \mathrm{C}$, respectively. The annual precipitation ranges from 500-720 mm, and decreases from southwest to northeast (Liu and Guo 2008; Chen and Dong 2009). Although the distribution of saline lakes is related to precipitation, 
temperature and net evaporation (Williams 1991), the limit at which saline lakes can exist is about equal to the $500 \mathrm{~mm}$ line of annual precipitation (Zheng 2010), and therefore saline lakes could have existed in some areas of this region. When the precipitation is significantly higher than $500 \mathrm{~mm}$, desalination occurs; when precipitation is too low, desiccation occurs.

Lacustrine sediments were identified in some isolated depressions of this region, which indicated that lakes had existed during the past several million years (Yan 1988; Zhao and Zhang 1994). A previous study obtained the quasi-continuous lake sediments over the past 34,000 years in the Lupotan Flats ('lu' means saline, 'po' means Lake, and 'tan' means Flats). However, sediments during the past 2000-3000 years were partially eroded and disturbed by human activities, thus hampering a reliable
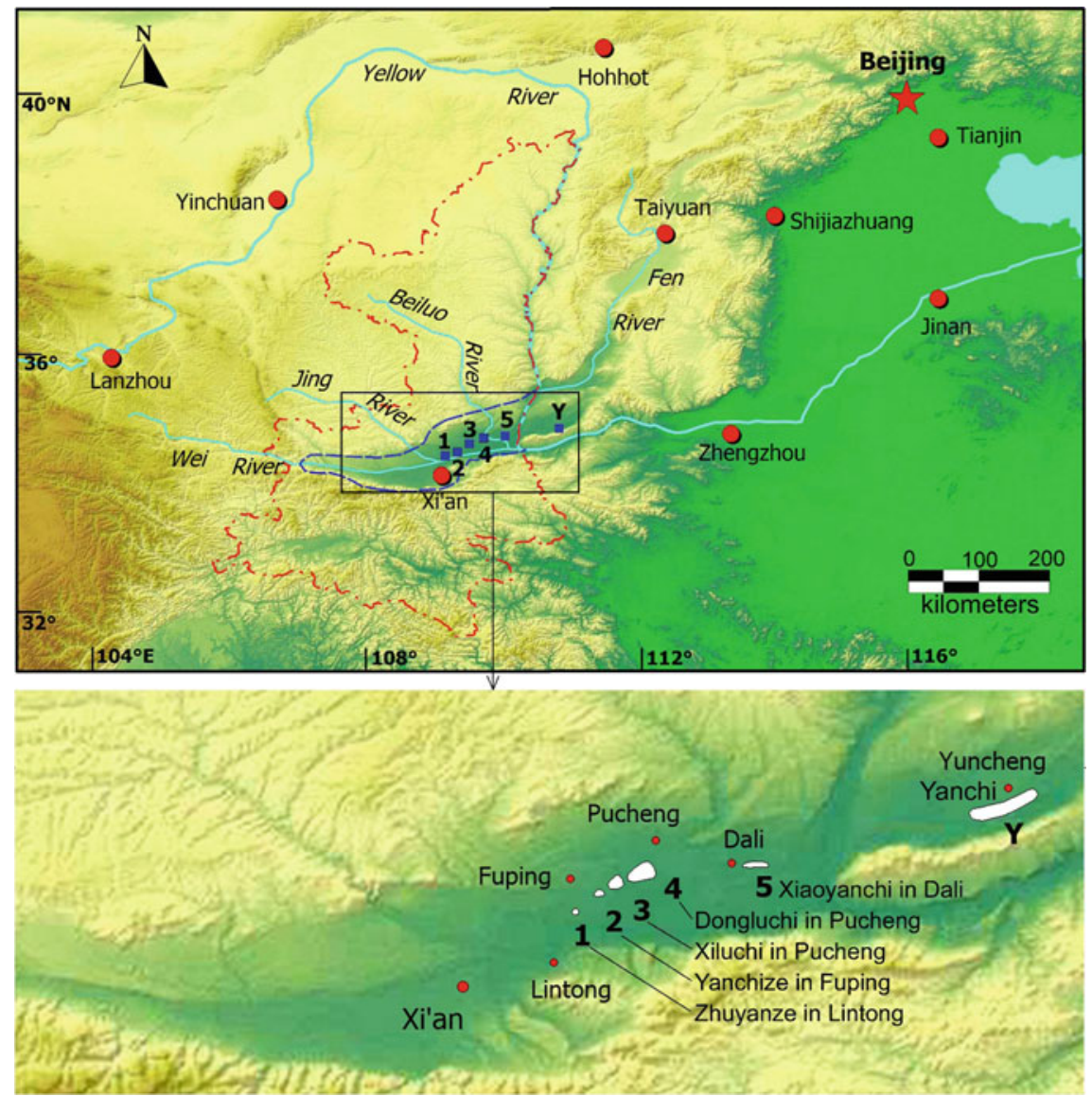

Fig. 2.1 Schematic map showing the recent topography of the Guanzhong Basin (upper panel) and the estimated locations of ancient saline lakes in the basin (lower panel). The Guanzhong Basin at the west of the Yellow River is indicated by blue dashed line, and the Shaanxi Province is in red dash-dotted line 
interpretation of the limnological information (Yan et al. 2016). Historical records, supplemented by archaeological evidence, are very reliable and effective.

\subsection{Materials and Methods}

Historical literature has been proven to be a critical source of information for gathering data on lake evolution during the past 2000 years (Brooks 1923; Dixey 1924; Nicholson 1999; Nicholson and Yin 2001; Fang 1993). The Guanzhong region is well known for its long history of civilization and abundant archives of historical literature. For this study, we examined the Chinese historical literature as well as archaeological materials (stone inscriptions), and investigated whether saline lakes existed in this region during the past 2000 years.

Various kinds of historical literature were examined, and relevant records were found in the historical local chronicles of the Fuping, Pucheng, Lintong and Dali counties and cities, historical chronicles of Shaanxi Province, dynastic histories, historical geography books, and stone inscriptions.

The data of population and cultivated lands of the relevant counties are scattered through the Chinese local historical chronicles. A systematic literature survey was conducted, and those of the Fuping, Pucheng, Lintong and Chaoyi counties are carefully examined. The population data were converted into population density data. With regard to the data of cultivated land, we employed a Cultivated Land Ratio (CLR), which was defined as the ratio between the cultivated land area and the total land area.

\subsection{Results}

After an exhaustive literature survey, nearly a hundred records concerning saline lakes were discovered. A synthesis of these records pointed to the existence of five historical saline lakes in the Guanzhong Basin, i.e. Lake Yanchize in Fuping County, Lakes Dongluchi and Xiluchi in Pucheng County, Lake Zhuyanze in Lintong County, and Lake Xiaoyanchi in Dali County (former Chaoyi County, Fig. 2.1). The five lakes will be discussed separately in the following sections.

\subsubsection{Lake Yanchize in Fuping County}

\subsubsection{Prior to the 13th Century}

Historical records on Lake Yanchize in Fuping County may be traced back to the Northern Wei Dynasty (386-534 AD). It was recorded in the History of the Northern 
Wei Dynasty that, 'there was a salt lake in the Pinyang County (modern Fuping County. Wei 554),

In the Yuanhe Reign Period General Geography (Li 813), it was recorded that, 'Lake Yanchize was located 25 li from the southeast of the administrative centre of the county (Fuping County). The circumference of the lake was 20 li.' Because the circumference was about $20 l i(1 l i \approx 0.5 \mathrm{~km})$, i.e. $10 \mathrm{~km}$, the area of the lake is estimated to have been about $4-8 \mathrm{~km}^{2}$. Similar records were also found in the New History of the Tang Dynasty (Song and Ouyang 1060), Chronicle of Chang' an (Song 1076) and Revised Chronicle of Chang' an (Luo 1296).

The earliest record is that which recorded the history of the Northern Wei Dynasty (386-534 AD). The latest record is that in the Revised Chronicle of Chang' an, which recorded the history prior to 1296 AD. Based upon the above sources, we inferred that Lake Yanchize was a saline lake with an area about $4-8 \mathrm{~km}^{2}$ between the late 4th and 13th centuries.

\subsubsection{14th-16th Centuries}

Two records were found in the Chronicle of Fuping County (Liu and Sun 1584),

The Lupotan Flats, was also known as the Mingshuitan Flats ('Mingshui' means water covered) and East Flats (Dongtan). The flats did not dry up in winter or summer, and the water could be boiled for extracting salt (Liu and Sun 1584).

Lake Yanze (i.e. Yanchize) lies in the east of the county, and looked like a lake (Liu and Sun 1584).

It may be inferred that Lake Yanze was still a saline lake during the 14th-16th centuries. However, the name of the lake was changed from ze (lake) to tan (flat), which possibly indicated that the lake had become significantly reduced in size.

\subsubsection{17th-18th Century}

Two brief records were found within two local chronicles which were printed in 1735 and $1740 \mathrm{AD}$ respectively.

(1) 'The Lupotan Flats lay in the east of the county, and now it was silted up.' (Liu and Shen 1735 . As indicated by the reference, 'now' probably refers to the early 18th century.)

(2) 'The Lupotan Flats, also known as the Mingshuitan Flats and East Flats. It was just the ancient Yanchi of Pinyang County. Now it dried up.' (Qiao 1740; Wu and $\mathrm{Hu}$ 1778; Fan and Liu 1891. As indicated by the references, 'now' probably refers to the early 18 th century.)

In addition, two official reports of the Lupotan Flat were recorded in the Draft Chronicle of Fuping County (Fan and Liu 1891), 
22nd Day, 7th month, 56th year, Qianlong Reign Period (21st Aug. 1791), the county head reported that 'there was no saline lake in Fuping County. But there is Luopotan Flat in the east of the county extending 6-7 li from east to west. The area is low and contains saline and alkali (that is, it contains $\mathrm{NaCl}$ and $\mathrm{Na}_{2} \mathrm{SO}_{4}$ ). When the weather is favourable, local people collected the surface soil, put it into water, and boiled it to extract salt. The salt is brackish (because it contains $\mathrm{Na}_{2} \mathrm{SO}_{4}$ ). When it rained too much, the flat was covered by water.

16th day, 11th month, 56th year, Qianlong Reign Period (16th Dec. 1791), the county head reported that 'the Lupotan Flat in our county was in all probability the Lake Yanchize in the chronicles... however, it dried up.

\subsubsection{19th Century}

An official investigation of the Lupotan Flats was conducted in the autumn of 1886 AD.

The Lupotan Flat in our county was the ancient Yanze Lake, and extends from Fuping to Pucheng. It was a saline land, local people took the saline soil after rains and boiled for Xiao (glauber's salt, i.e. Sodium Sulfate Decahydrate).

The flats in Fuping County extended 3-4 li from east to west, and 2-3 li from north to south... The area was full of weeds and contained no saline waters, and the areas that still possessed salt production extends to less than 1 square li $\left(1\right.$ square li $\left.\approx 0.25 \mathrm{~km}^{2}\right) \ldots$ there were only five or six small ponds that were producing salt, other areas were wastelands and were overgrown with weeds (Fan and Liu 1891).

According to the investigation, the flats in Fuping County were dry by the late 19th century. In addition to the official report of the investigation, a few related materials were recorded in the Draft Chronicle of Fuping County. In conclusion, the above records indicate that Lake Yanchize in Fuping County (also known as the Lupotan Flats) had desiccated at some point during 1584-1735 AD.

\subsubsection{Lakes Dongluchi and Xiluchi in Pucheng County}

Lakes Dongluchi and Xiluchi lay in the south of the Pucheng County. Here, 'dong' means 'east', 'xi' means 'west', and 'luchi' means 'salt lake'. Historical records on Lakes Dongluchi and Xiluchi in Pucheng County are numerous and very detailed.

\subsubsection{Prior to the 13th Century}

As early as 2000 years ago, the History of the Western Han Dynasty (Ban et al. 80) recorded that 'Emperor Xuandi (reign in 91-49 BC) was trapped in Luzhong, Lianshao County... There was a salt lake in the Lianshao County, and it extended over $10 \mathrm{li}$ from north to south. The local people called it Luzhong.' The Lianshao County during the Han Dynasty lay near the modern Lupotan Flats (Tan 1982), and 
Lake Luzhong should be the possible predecessor of Lakes Dongluchi and Xiluchi, as well as the modern Lupotan Flats.

No relevant historical records are available concerning the Three Kingdoms Period (220-265 AD), but archaeological evidence has been identified. Archaeological research unearthed two official seals, one is 'Lianshao Lu Xian Du Yin' (Seal of the Lianshao Governor of Salt and Alkali Industries), and the other is 'Lianshao Lu Du Yin' (Seal of the Lianshao Governor of Salt Industry) (Luo 1987). The seals support the idea that there was salt production during the Three Kingdoms Period, which thus possibly indicates the existence of one or more salt lakes in this region, as there are no salt mines or dry lake salt crusts in this region.

Detailed historical records become available again from the Tang Dynasty (618-907 AD). The Luchi Lakes (including the Dongluchi and Xiluchi lakes) of Fengxian County (modern Pucheng County) were recorded as one of the salt production places in the History of the Tang Dynasty (Liu 945), New History of the Tang Dynasty (Song and Ouyang 1060) and the Collection of Material on the Lives of Emperors and Ministers (Wang 1013).

\subsubsection{14th-17th Centuries}

Detailed records are available concerning the Ming and Qing Dynasties (1368-1644 AD, 1644-1911 AD). In the History of the Ming Dynasty (Zhang 1739), it was recorded that 'there were Xiluchi in the west Pucheng County and Dongluchi in the south Pucheng County, and salt was produced previously.'

A poem titled 'Bing qi ri ji (Sunshine on the ice covered salina)' was recorded in the Continued Chronicle of Pucheng County (Wang and He 1714). The date of the poem was sometime during the Ming Dynasty. The poem probably refers to the Xiluchi Lake or the Dongluchi Lake, as there were only two saline lakes in Pucheng County. This poem indicated that saline lakes and salt production existed in Pucheng County during the Ming Dynasty (1368-1644 AD).

Within the Chronicle of Pucheng (Deng and Li 1666), three records are identified:

(1) 'There is a saline lake looking like a mirror in the south of the county.'

(2) 'East Luchi Lake lies 20 li to the south of the city centre of the county, and it was also called Anfengtan Flats. Salt was formed naturally in the 12th year of Dali Reign Period (777 AD). After that, salt production in the salt lake was forbidden, but alkali production went on.'

(3) 'West Luchi Lake lies 40 li to the southwest of the city centre of the county... it did not dry up even in droughts. The local people boiled the lake water and extracted salt. Recently, salt production was given up because of the high cost.' 


\subsubsection{18th Century}

In the Draft Chronicle of Fuping County, a detailed report on the Lupotan Flats, entitled Hui Kan Lu-po-tan Bin (Report of the joint investigation of the Lupotan Flats), was provided (Fan and Liu 1891; Li and Wang 1905).

The Lupotan Flats included the former East Luchi, West Luchi, and Yanchize lakes. The report was based on an official investigation of the Lupotan Flats in autumn 1791 AD.

It was said that the Lupotan Flats extended 50-60 li from east to west. The East Flats extended 5-6 li. The middle part of the Lupotan, extending 30-40 li, was a wasteland. The West Flats extended about $10 \mathrm{li}$. The end part of the Lupotan, extending a little more than $1 \mathrm{li}$, was overgrown with weeds. Apart from the middle and end sections, the flats extended a little more than 10 li. Ever since the Tang Dynasty, salt production left numerous deserted ponds, and saline water dried. There were salt production operations only in a few square li of the flat now.

We investigated the East Flats and learned that saline water existed in the middle of the East Flats, and was surrounded by wheat fields... we criticized that they were producing salt illegally, and it was told that it was not salt but mirabilite. They told us that of the products in the flats, $90 \%$ was mirabilite, and $10 \%$ was salt.

Then, we investigated the West Fats. They lie between Pucheng and Fuping counties, and mostly in Pucheng. We walked for two days, and saw no people, but only desert and weeds. The ponds were old and long abandoned.

According to this report, the East Flats, i.e. the former East Luchi Lake, desiccated before 1791 AD; The West Flats, i.e. the former West Luchi Lake and the Yanchize Lake, also completely desiccated. Inferring from the print dates of the literature, both the East and West Flats probably desiccated during the years 1666-1791 AD.

\subsubsection{Late 19th Century and Early 20th Century}

Maps recorded the lakes of Pucheng County in the Shaanxi Provincial Atlas (Wei 1899) and the New Chronicle of Pucheng County (Li and Wang 1905). The West Luchi Lake was drawn as Lupotan (Saline Lake Flats) in these maps. A road was drawn in the Lupotan (Xiluchi Lake) in the map in the New Chronicle of Pucheng County, thus providing evidence that the Xiluchi Lake probably desiccated around 1890-1910.

An atlas was made in 1915 AD by the Japanese Territorial Geodesy Department (1938). According to the atlas, the west and middle areas of the Lupotan Flats were dry in 1915. The east part of the Lupotan Flats also desiccated except for several ponds scattered around the flats.

It may be inferred from these sources that the Lupotan Flats, including Xiluchi Lake, Dongluchi Lake and Yanchize Lake, desiccated earlier than the late 19th century and early 20th century. This is consistent with the above inference that the lakes desiccated during the period 1666-1791 AD. 


\subsubsection{Lake Zhuyanze in Lintong County}

Lake Zhuyanze lies in Lintong County. The earliest record of this lake was identified in the Yuanhe Reign Period General Geography. It was recorded that,

Lake Zhuyanze lies 15 li to the south of the Yueyang County. The lake's water contains a lot of salt. People boiled the water and extracted salt during the Fuqin Period (350-394 AD).

The circumference of the lake was 20 li. (Li 813)

A similar record was found in the Chronicle of Chang' an (Song 1076) which was compiled in the late 11th century. The New History of the Tang Dyansty contains a chapter that recorded the lakes that yielded salt, and Lake Zhuyanze was one of them. It was recorded that, 'there was a Lake Zhuyanze in the Yueyang County.' (Modern Yueyang Town of Lintong County) (Song and Ouyang 1060) 600 years later, the Chronicle of Lintong County repeated this record, and added one more sentence, 'the water in the Zouma village was salty now. A lake is supposed to have existed here (Zhao 1701).' Because the Chronicle of Chang' an was printed in 1076 AD, and the Chronicle of Lintong County was printed in $1701 \mathrm{AD}$, the date of the desiccation of the lake should be sometime in the period 1076-1701 AD.

\subsubsection{Lake Xiaoyanchi in Dali County}

The earliest record of Lake Xiaoyanchi in Chaoyi County ${ }^{1}$ was found in the History of the Tang Dynasty which listed Lake Chaoyi Xiaochi as a salt production place (Liu, 945).

In the New History of the Tang Dynasty, it was recorded that 'salt was manufactured in Lake Xiaochi, Chaoyi County' (Song and Ouyang 1060). In the Chronicle of Tongzhou Prefecture (Zhang and Ma 1625), it was recorded that

'Salt was produced in Lake Xiaoyanchi during the Tang Dynasty. Now, salt was not manufactured regularly, and the output was very limited.'

It was then recorded in the Continued Chronicle of Chaoyi County (printed in 1712 AD. Wang 1712) that

The water of the area gathered in Lake Xiaoyanchi. It was extremely arid in this area. By boiling the water, salt was extracted.... When it was rainy, salt could not be produced... The basin extended more than $20 \mathrm{li}$, and the soil was saline. Crops could not grow, whereas wild grass grew everywhere.

In addition, it was recorded in this chronicle that there was illegal salt production, whereas salt production was officially organized in the Wanli Reign Period (1573-1620 AD).

These records indicate that Lake Xiaoyanchi was still a salt lake in the early 18th century. However, in the Chronicle of the Chaoyi County, it was recorded that Lake

\footnotetext{
${ }^{1}$ Chaoyi County was merged into Dali County in 1958.
} 
Table 2.1 Historical saline lakes in the Guanzhong Region ${ }^{\mathrm{a}}$

\begin{tabular}{l|l|l|l|l}
\hline Name & Location & Size $\left(\mathrm{km}^{2}\right)$ & Type & Desiccation \\
\hline Yanchize & Fuping County & $4-8$ & Chloride and sulphate & $1584-1735$ AD \\
\hline Xiluchi & Pucheng County & Several & Chloride and sulphate & $1666-1791$ AD \\
\hline Donglu Chi & Pucheng County & Several & Chloride and sulphate & $1666-1791$ AD \\
\hline Zhuyanze & Lintong County & Several & Chloride & $1076-1701$ AD \\
\hline Xiaoyanchi & Dali County & Several & Chloride & $1712-1906$ AD \\
\hline
\end{tabular}

${ }^{a}$ The sizes of the lakes are estimated according to the circumferences and relevant records. The types of the lakes are based on the historical records of salt production and Xiao (Glauber's salt. $\mathrm{Na}_{2} \mathrm{SO}_{4} \cdot 10 \mathrm{H}_{2} \mathrm{O}$ ) production

Xiaoyanchi was abandoned in later times. The area occupied by Lake Xiaoyanchi was called 'Yanchiwa', which means a flat called Yanchi (Zhu 1906). The lake, by this time, probably desiccated and was possibly reduced to an inland salt marsh.

According to the timing of the chronicles compiled, we infer that Lake Xiaoyanchi desiccated and was possibly reduced to an inland salt marsh sometime in the years 1712-1906 AD.

In summary, the evolution of the five historical saline lakes is reconstructed using historical records (Table 2.1). Historical records about the three Lupotan lakes were found to be numerous, whereas records on the Zhuyanze and Xiaoyanchi lakes are relatively rare. All the saline lakes lie in the relatively arid northeast part of the Guanzhong Region. Among them, Lakes Dongluchi, Xiluchi and Yanchize lie in an area commonly known as the Lupotan Flats where lacustrine sediments were identified, indicating the existence of saline lakes during the past several million years (Yan 1988; Zhao and Zhang 1994).

\subsection{Discussions}

\subsubsection{Causes of the Degradation and Desiccation of the Saline Lakes}

Despite the presence of historical records and the plethora of evidence they contain, a fundamental question remains to be ascertained. What is the cause of the disappearance of these lakes? The causes of the drying up of saline lakes maybe complicated, and various causes need be considered. 


\subsubsection{Climatic Change}

Climatic change is commonly considered a major force behind lake evolution (Fang 1993; Ma et al. 2010). Here we discuss the climatic background of the saline lake evolution in the Guanzhong Basin.

With regard to precipitation, we employed the six-grade data set of drought or flood of Shaanxi Province (Yuan 1994). The data set is based on various historical records, and the starting point is $580 \mathrm{AD}$. Droughts and floods are classified into six grades according to their respective severity. We calculated the decadal arithmetic mean of the grades of droughts and floods as an indicator of precipitation (Fig. 2.2d) (Yuan 1994).

It seems that the dry period of the 15th-17th centuries overlapped with the periods that the lakes Yanchize, Xiluchi and Dongluchi possibly desiccated. We compared the lake evolution with a recently updated set of chronology for temperature changes in China based on multiple sources (Fig. 2.2e) (Ge et al. 2013). A comparison with temperature change chronologies indicates that Lakes Yanchize, Dongluchi, Xiluchi and Xiaoyanchi desiccated in the cold period of 14th-19th centuries, but the relationship is not very clear.

As a whole, the desiccation of the historical saline lakes usually occurred in relatively dry periods. A possible explanation is that the humid summer monsoon was weak during the Little Ice Age (Zhang et al. 2008).

\subsubsection{Silt Sedimentation}

A previous study indicated that sediment accumulation caused the filling of lake basins and contributed significantly to the drying up of lakes in the lower reaches of the Yellow River Plain (Fang 1993). The middle reaches of the Yellow River are well known for severe soil erosion. Figure 2.2c shows the sediment outputs of the upper and middle reaches of the Yellow River, which illustrates how many tons of silt and sand were transported by the Yellow River. About $90 \%$ of the sediment outputs come from the middle reaches. Therefore, the erosion of the middle reaches of the Yellow River increased over time during the last 2000 years (Xue 2001; Shi 2009).

Is silt sedimentation the cause of the desiccation of Lakes Dongluchi, Xiluchi and Yanchize in Pucheng and Fuping counties? The Draft Chronicle of the Pucheng County recorded,

The East and West Luopo Flats lay in the south of the county (Pucheng County)... The salt lake in Pucheng had a poor fate. Ever since the times of antiquity, no one protected it, and no one developed it. Every year it was flooded by the mountain floods, whereby sand and silt were deposited. Year after year, it was further reduced to dry flats. (Institute of Pucheng County 1946)

An earlier source also briefly recorded the cause of the desiccation of the Lupo Flats. It was recorded that 'The Lupo Flats lay in the east of the county (Fuping County), and it was silted up now.' (Liu and Shen 1735). The records on Lake 

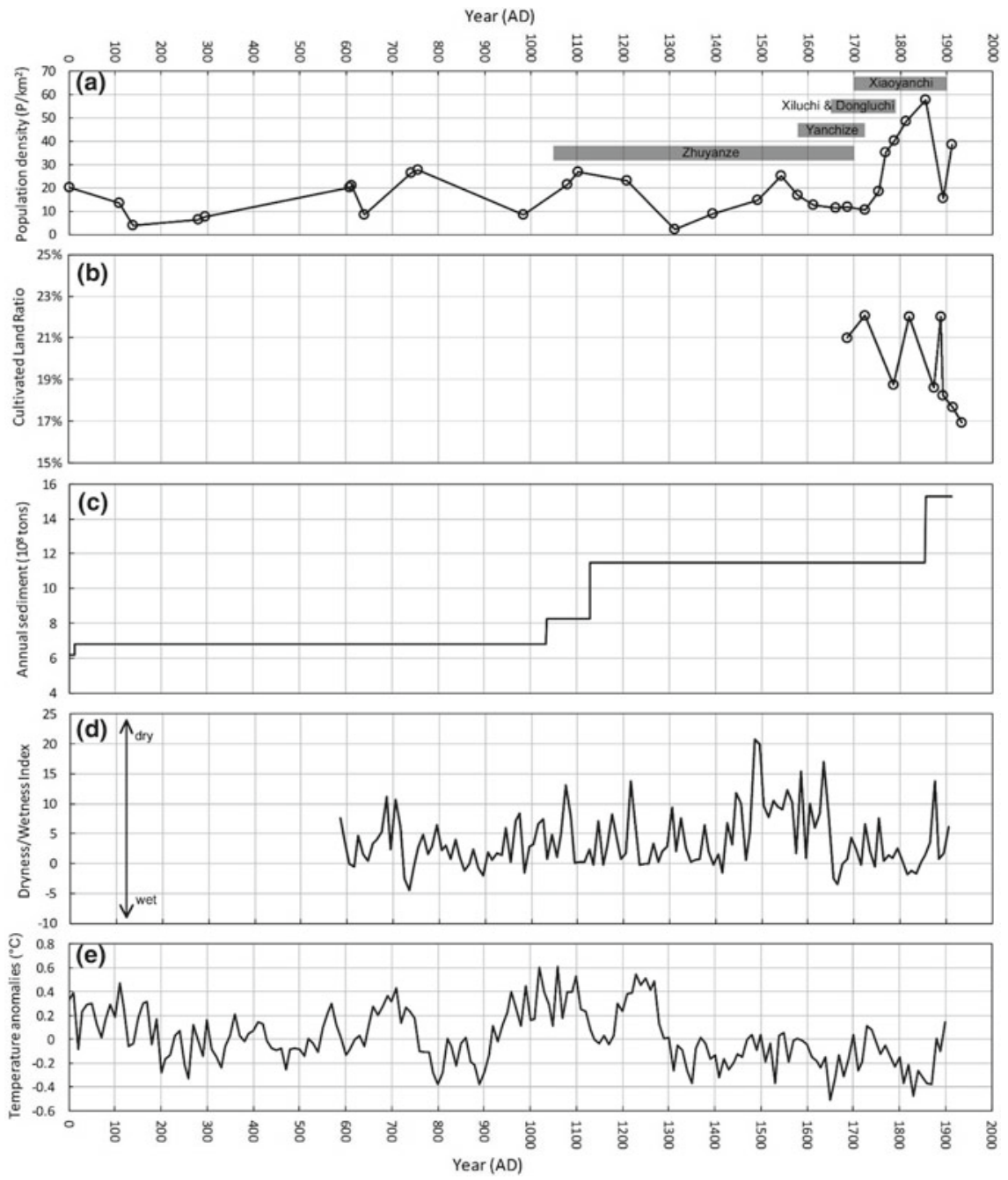

Fig. 2.2 a Evolution of the population density of Shaanxi Province during the past 2000 years (Xue 2001). The bars denote the approximate dates that the lakes desiccated. $\mathbf{b}$ The cultivated land ratio of Shaanxi Province ( $\mathrm{Ge}$ et al. 2004). $\mathbf{c}$ The annual sediment outputs from upper and middle reaches of the Yellow River (Shi 2009). d The dryness/wetness index change of Xi' an and Yan' an (Central Meteorological Administration of China 1981). e The annual temperature anomalies in China (Ge et al. 2013). Edited by Liang Emlyn Yang

Zhuyanze are relatively terse, and it is difficult to determine precisely when it desiccated. The topography might have contributed to the desiccation of the lake. Lake Zhuyanze was very close to the channel of the Weihe River, which frequently caused flooding during the past 2000 years (Yin et al. 2005). River flooding and the resulting silt sedimentation are a potential cause of the desiccation of Lake Zhuyanze. 
Lake Xiaoyanchi evolved from a saline lake to a salt flat during the 18th-19th centuries. This lake was very close to the channel of the Beiluo River, which flooded and migrated frequently over the past 2000 years of history (Wang 2005). Therefore, the evolution and shrinking of the lake is possibly also related to the river flooding and the resulting silt sedimentation.

However, historical records concerning Lakes Zhuyanze and Xiaoyanchi are relatively brief, and no sources clearly recorded that these two lakes were directly flooded by the Weihe and Beiluo Rivers. The link between the evolution of the two lakes and river flooding remains inevitably hypothetical.

\subsubsection{Population Density and Cultivated Land Area}

In an agricultural society, increased population causes expanding areas of cultivated lands. Population pressure and cultivated lands were discussed on both provincial and national levels. The population and cultivated land changes at the county level offer a detailed relationship between specific saline lake evolutions and population and cultivated land changes. The saline lakes' basins were enclosed drainage basins, and these lakes were small and only occupied certain parts of the counties. The comparison of population change on countywide levels would be more informative than other approaches.

The population data were divided by the area data and converted into population density, which is helpful to understand historical population pressure. Previous researches have integrated the data sets of the historical population and cultivated land of Shaanxi Province (Xue 2001; Ge et al. 2004). Among them, Xue's (2001) data set of the historical population sizes of Shaanxi Province during the past 2000 years is of good quality. We used this to indicate the population density change there. The population density of Shaanxi Province fluctuated during the 1st-17th centuries, and increased dramatically since the 18 th century (Fig. 2.2a).

Historical records of cultivated lands are less detailed in comparison to those of population, and that of Ge et al. (2004) is the only available data set of the cultivated land data of Shaanxi Province in historical times (Fig. 2.2b). The Lakes Yanchize, Dongluchi, and Xiluchi desiccated sometime during the years 1666-1791 AD, and Lake Xiaoyanchi desiccated during 1712-1906 AD, which corresponds to the population explosion in Shaanxi Province during the 18th-19th centuries (Fig. 2.2a). Concerning the CLR of Shaanxi Province during the past 400 years, its relationship with the saline lake evolutions is not very significant (Fig. 2.2b).

We compared the population density and CLR of Lintong County, Fuping County, Pucheng County, and Chaoyi County (Fig. 2.3) with the dates of the desiccation of Lakes Zhuyanze, Yanchize, Dongluchi-Xiluchi, and Xiaoyanchi, respectively. The population density and CLR in this region in historical times were very high. It is clear that the desiccation of Lake Yanchize and Lakes Dongluchi-Xiluchi corresponds to periods of population explosion and elevated CLR in Fuping and Pucheng Counties (Fig. 2.3). The desiccation of these lakes is apparently related to the mas- 


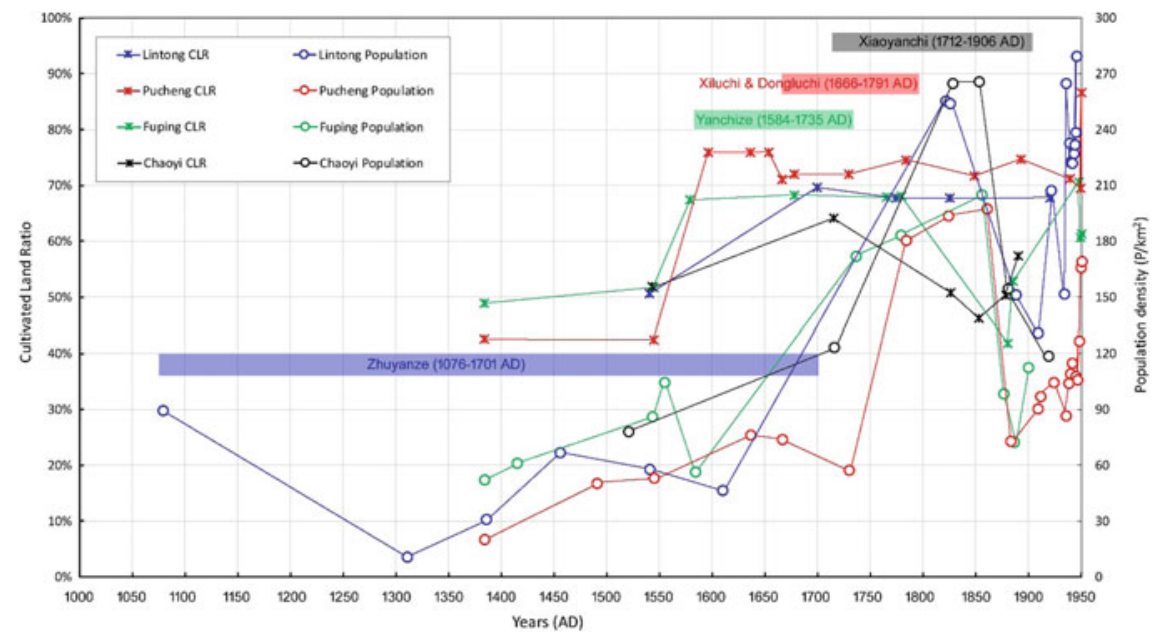

Fig. 2.3 The Cultivated Land Ratio (CLR) and population density of the four counties Lintong, Pucheng, Fuping and Chaoyi during the years 1000-1950 AD. The bars denote the approximate desiccation dates of the five lakes with the bar colour indicating the lake locations at the counties. Edited by Liang Emlyn Yang

sively increased population pressure on the region's natural environment, leading to increased soil erosion, increased sediment accumulation and lake reclamation.

With regard to Lake Zhuyanze in Lintong County and Lake Xiaoyanchi in Chaoyi County (Fig. 2.3), the relationship with population and cultivated land are not clear. In particular, the time that Lake Zhuyanze desiccated was deduced to be in the range of 1076-1701 AD, which is too long and difficult to be discussed in detail.

In addition, population pressure also caused the destruction of forests. A qualitative study suggested that the forests on the Loess Plateau reduced gradually during the past 2000 years, which resulted in an increase of the rate of soil erosion and accelerate the silting up of lakes in the region (Shi 2001).

\subsubsection{Flood Irrigation and Reclamation}

A map engraved on a stone in Fuping County, Shaanxi Province, recorded that the silty flood carried by the gully stream, Zhaolaoyu, flowed to the saline flat Lupotan and made it reclaimable (Fig. 2.4). The map was engraved in 1670 AD, thus the map was drawn during the period that the three lakes, Yanchize, Xiluchi and Dongluchi, in the Lupotan region were shrinking or about to shrink. It indicates that the silt carried by flood irrigation was possibly related to the desiccation of these lakes.

Some researchers argued that the flood irrigation possibly had a history of 2000 years in the Guanzhong Basin, though the historical records and evidence are brief and ambiguous (Ye 1991, 1992; Chang 1997). Few historical records are 
Fig. 2.4 Part of the geographical map of Fuping (Fuping yuditu. Shen Qiqian, 1670. The map was engraved on a stone, and the stone is archived in the Fuping County Library, Shaanxi Province, China). The letters A, B, C, D are added by the authors. 'A' denotes the text that reads 'Lupotan (a saline flat)'. 'B' denotes the text that reads 'the silt carried by the gully stream deposited in the flat and made it reclaimable'. ' $\mathrm{C}$ ' denotes the text that reads 'Zhaolaoyu (a gully stream).' ' $D$ ' denotes the boundary between Fuping and Pucheng counties

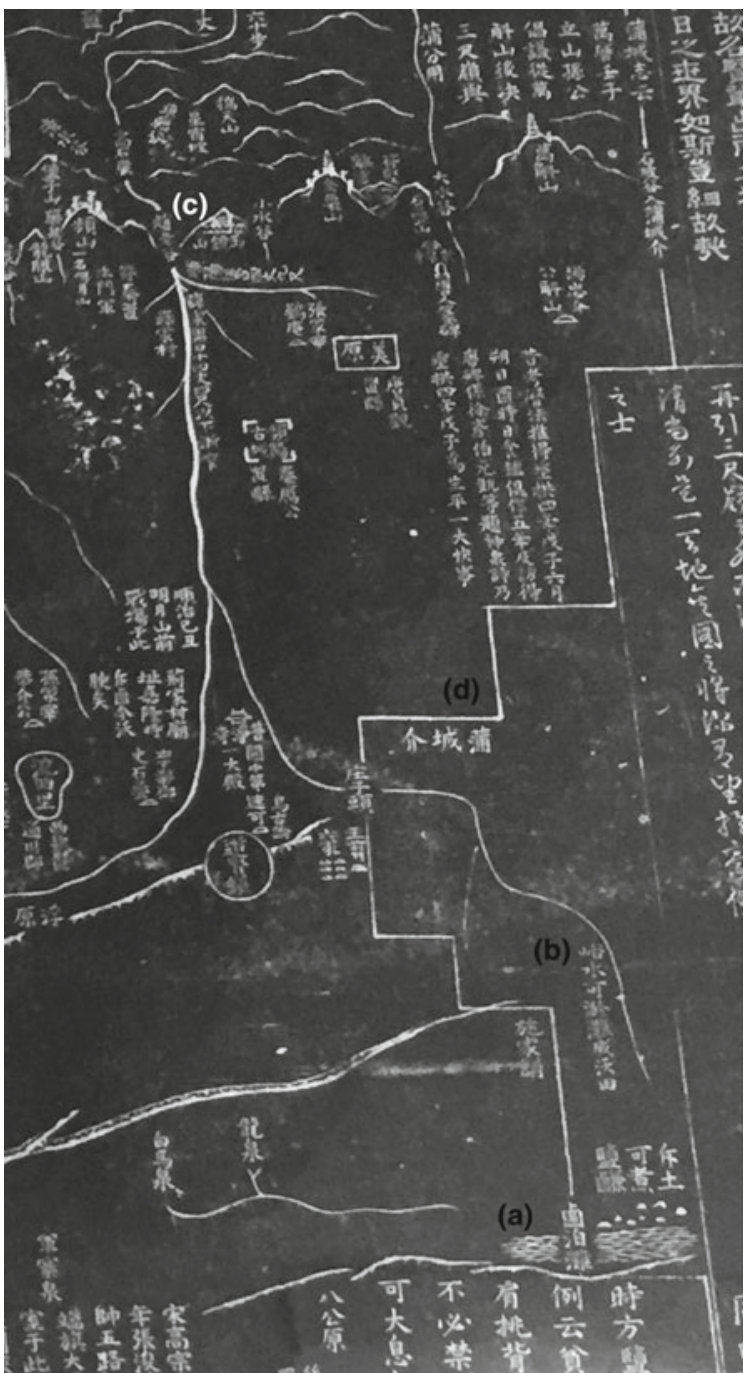

available concerning unambiguous description of flood irrigation, and no evidence indicates that it was extensive and long-lasting in this region prior to the Qing Dynasty (1644-1912) (Ye 1991, 1992; Chang 1997). 


\subsubsection{Relationship with the Sanmen Paleo-Lake}

During the Pliocene (5.3-2.6 Ma BP) and Pleistocene (2.6-0.01 Ma BP) epochs, there was a large Sanmen Paleo-Lake in the modern plains of the Weihe and Fenhe rivers (Anderson 1923; Wang et al. 1999). The area of the Sanmen Palaeolake varied during the Quaternary Period, and the maximum extent was about equal to the modern plains.

Stratigraphical research indicates that it was most probably a saline lake which was drained about $0.15 \mathrm{Ma} \mathrm{BP}$, when the mountain to the east of the lake was cut through by the paleo Yellow River, thus forming the modern Yellow River (Wang et al. 2001, 2004; Zhang et al. 2004; Liu et al. 2006; Jiang et al. 2007). The Yellow River flowed through the modern Sanmenxia Gorge and eventually drained into the sea. The Sanmen Paleo-Lake shrank and resolved into several relatively small lakes. There is Lake Yuncheng Yanchi (Yuncheng Salt Lake), along with a few small saline lakes in the lower reaches of the Fenhe River, even in modern times, which comprise the remains of the Sanmen Paleo-Lake.

Previous researchers suggested that the remains of the Sanmen Paleo-Lake had existed as several isolated saline lakes in the Guanzhong Basin during the Pleistocene Epoch (Yan 1988; Zhao and Zhang 1994) and early Holocene (Yan et al. 2016). In particular, late Quaternary and early Holocene lacustrine sediments were identified in the Lupotan region (Luopotan Flats), an isolated depression where Lakes Yanchize, Xiluchi and Dongluchi existed (Yan 1988; Zhao and Zhang 1994). Recent research confirmed the quasi-continuous existence of lake sediments in the Lupotan Flats, and the paleolake possibly desiccated ca. 4600 years ago (Yan et al. 2016). The sediments during the past 4600 years were disturbed by increasingly intense human activities, and the lake evolution history of this period remains uncertain.

Regarding Lake Zhuyanze in Lintong County and Lake Xiaoyanchi in modern Dali County, there is no doubt that these regions were parts of the Sanmen PaleoLake before the middle Pleistocene, but no stratigraphical research has been done concerning the lake evolution in the late Pleistocene and the Holocene. Because lake remains most probably exist, our inferences at least support the evidence for smaller remaining lakes of the Sanmen Paleo-Lake in historical times.

Our inference on the existence of historical saline lakes suggests that the remains of the Sanmen Paleo-Lake still existed in the northeast part of the Guanzhong Basin during the past 2000 years. This result improves the understanding of the temporal and spatial history of the Sanmen Paleo-Lake. 


\subsection{Conclusions}

There are no saline lakes in the Guanzhong Basin in modern times. Using Chinese historical sources and archaeological materials, we inferred the existence of five historical saline lakes in the region during the past 2000 years, i.e. Lakes Yanchize, Xiluchi, Dongluchi, Zhuyanze and Xiaoyanchi.

Lakes Zhuyanze, Yanchize, Xiluchi, Dongluchi, and Xiaoyanchi desiccated sometime during 1076-1701 AD, 1584-1735 AD, 1666-1791 AD, 1666-1791 AD, and 1712-1906 AD, respectively. Most of the lakes desiccated during cold climate conditions. The dry period of the 15 th -17 th centuries overlapped with the periods that some of the lakes desiccated. However, the relationship is not very clear.

The lakes in the west of this region possibly desiccated relatively early, and the lakes in the east desiccated relatively late, but the reasons remain unknown. All the five lakes desiccated during periods of increased soil erosion. Flood irrigation and silt sedimentation were probably the main causes of the desiccation of Lakes Yanchize, Xiluchi and Dongluchi.

The desiccation of Lake Yanchize and Lakes Dongluchi and Xiluchi correspond to periods of population explosion and more land was cultivated in Fuping and Pucheng Counties. Population pressure, increased levels of cultivated lands and soil erosion are the potential causes of the desiccation of these historical saline lakes.

Acknowledgements The helpful comments of Professors Koichi Muramatsu, Kazuyuki Tsuruma and Yongjian Hou are much appreciated. An earlier version of this research paper was included in the 2017 Research Report of the Institute of International Research and Education of Gakushuin University (in Japanese). The research was supported by the Shanghai Municipal Philosophy and Social Sciences Grant (No. 2017BLS003) and the National Natural Sciences Foundation of China (Grant No. 41672180).

\section{References}

Anderson, J. G. (1923). Essays on the cenozoic of Northern China. Memoirs of the Geological Survey of China (Series A), 3, 1-93.

Brooks, C. E. P. (1923). Variations in the level of Lake George, Australia. Nature, 112, 918.

Chang, S. (1997). New research on the area of flood irrigation of the irrigation Canal Zhengguoqu. Journal of Chinese Historical Geography (Zhongguo Lishi Dili Luncong), 4, 189-194. (in Chinese).

Chen, T., \& Dong, J. (2009). An analysis on characteristics of climatic changes in Guanzhong Plain in recent 49 year. Journal of Arid Land Resources and Environment, 23, 76-81. (in Chinese).

Dixey, F. (1924). Lake level in relation to rainfall and sunspots. Nature, 114, 659-661.

Fang, J. (1993). Lake evolution during the last 3000 years in China and its implications for environmental change. Quaternary Research, 39, 175-185.

Ge, Q., Dai, J., He, F., Zheng, J., Man, Z., \& Zhao, Y. (2004). Spatiotemporal dynamics of reclamation and cultivation and its driving factors in parts of China during the last three centuries. Progress in Natural Science, 14, 605-613.

Ge, Q., Hao, Z., Zheng, J., \& Shao, X. (2013). Temperature changes over the past $2000 \mathrm{yr}$ in China and comparison with the Northern Hemisphere. Climate of the Past, 9, 1153-1160. 
Jiang, F., Fu, J., \& Wang, S. (2007). Formation of the Yellow River, inferred from loess-palaeosol sequence in Mangshan and lacustrine sediments in Sanmen Gorge, China. Quaternary International, 175, 62-70.

Liu, J., \& Guo, R. (2008). Analysis of the characteristics of the precipitation in the Guanzhong Plain. Yellow River, 30, 22-24. (in Chinese).

Liu, H. J., Xue, X. X., \& Li, Y. X. (2006). Calculation on the paleosalinity of the ancient Sanmen Lake in the Weinan Area of Weihe River Basin. Journal of Northwest University (Natural Science Edition), 36, 112-114. (in Chinese).

Luo, F. Y. (Ed.). (1987). Collection of Official seals during the Qin and Han Dynasties and the Southern and Northern Dynasties. Beijing: Historical Relics Press. (in Chinese).

Ma, R., Duan, H., Hu, C., Feng, X., Li, A., Ju, W., et al. (2010). A half-century of changes in China's lakes: Global warming or human influence? Geophysical Research Letters, 37, L24106. https:// doi.org/10.1029/2010g1045514.

Nicholson, S. E. (1999). Historical and modern fluctuations of lakes Tanganyika and Rukwa and their relationship to rainfall variability. Climatic Change, 41, 53-71.

Nicholson, S. E., \& Yin, X. (2001). Rainfall conditions in equatorial East Africa during the 19th century as inferred from the record of Lake Victoria. Climatic Change, 48, 387-398.

Shi, N. H. (2001). Historical geography research of the Loess Plateau. Yellow River Water Conservancy Press. (in Chinese).

Shi, C. X. (2009). Sedimentation in the lower reaches and sediment yield in the upper and middle reaches of the Yellow River in the past 2600 years. Quaternary Sciences, 29, 116-125. (in Chinese).

Tan, Q. (1982). The historical atlas of China (Vol. 2). Beijing: China Cartographic Publishing House. (in Chinese).

The General Office of the Japanese Territorial Geodesy Department. (1938). Topographical Atlas of China (1:50,000). Pages of Guanlu Town and Guanshan Town (in Japanese). The atlas was drawn in 1915 AD and was published in 1938 AD. A copy of the atlas was archived in the Fudan University Libraries.

Wang, Y. (2005). Physical environmental change in the basins of the Jing and Luo rivers. Beijing: Zhonghua Book Company (Zhonghua Shu Ju). (in Chinese).

Wang, S., \& Dou, H. (1998). Encyclopaedia of the lakes in China (pp. 301-304). Beijing: Science Press. (in Chinese).

Wang, S., Jiang, F., Wu, X., et al. (1999). A study on the age of Sanmen group in Sanmenxia area. Journal of Geomechanics, 5(4), 57-65. (in Chinese).

Wang, S. M., Wu, X. H., Zhang, Z. K., et al. (2001). Environmental evolution and the eastward flowing of the Yellow River recorded by the sediments of the Paleo-Sanmen Lake. Sciences in China (D), 31, 760-768. (in Chinese).

Wang, S. B., Jiang, F. C., Wu, X. H., et al. (2004). The connotation and significance of Sanmen formation. Quaternary Sciences, 24, 116-123. (in Chinese).

Williams, W. D. (1991). Chinese and Mongolian saline lakes: A limnological overview. Hydrobiologia, 210, 39-66.

Xue, P. (2001). Shaanxi historical population geography. Beijing: The people's press. (in Chinese).

Yan, Y. (1988). The environmental changes, exploitation and utilization of the Luyang Lake Basin. Geology of Shaanxi, 6, 65-75. (in Chinese).

Yan, Y., Zhou, J., He, Z., et al. (2016). Evolution of Luyang Lake since the last 34,000 years: Climatic changes and anthropogenic impacts. Quaternary International, 440, 90-98.

Ye, Y. (1991). From Zhengguoqu (Irrigation Canal Zhengguoqu) to Jinghuiqu (Irrigation Canal Jinghuiqu). People's Yellow River (Renmin Huanghe), 4, 66-70. (in Chinese).

Ye, Y. (1992). The past and present of the Zhaolaoyu flood irrigation area. Ancient and Modern Agriculture (Gujin Nongye), 1, 64-65. (in Chinese).

Yin, S., Huang, C., \& Li, X. (2005). Historical drought and water disasters in the Weihe Plain. Journal of Geographical Sciences, 15, 97-105. (in Chinese). 
Yuan, L. (1994). Northwest disasters history (Xibei zaihuang shi). Lanzhou: Gansu People's Press (Gansu Renmin Chubanshe). (in Chinese).

Zhang, P., Cheng, H., Edwards, R. L., et al. (2008). A test of climate, sun, and culture relationships from an 1810-year Chinese cave record. Science, 322. https://doi.org/10.1126/science.1163965.

Zhang, Z., Wang, S., Yang, X., et al. (2004). Evidence of a geological event and environmental change in the catchment area of the Yellow River at 0.15Ma. Quaternary International, 117, $35-40$.

Zhao, S., \& Zhang, F. (1994). On stratum lithology, saline-alkali mineral and formation environment of Lu Bo Tan in Shaanxi. Journal of Northwest University of Architecture and Engineering, 3, 12-19. (in Chinese).

Zheng, M., Tang, J., Liu, J., \& Zhang, F. (1993). Chinese saline lakes. Hydrobiologia, 267, 23-36.

Zheng, X. Y., et al. (2002). Encyclopaedia of the salt lakes in China (pp. 1-413). Beijing: Science Press. (in Chinese).

Zheng, M. (2010). Salt lake resources and eco-environment in China. Acta Geologica Sinica, 84, 1613-1622. (in Chinese).

\section{Chinese Historical Documents}

Ban, G., Ban, B., Ban, Z., Ma, X. (finished the book in 80 AD), Yan, S., et al. (added notes in circa 640 AD). (1962). History of the Western Han Dynasty (Han Shu), Vol. 8. Published by the Zhonghua Book Company, Beijing, 1962. (in Chinese).

Deng, Y., \& Li, F. (1666 AD). Chronicle of Pucheng (Pucheng Zhi), Vol. 1. (in Chinese).

Fan, Z., \& Liu, K. (1891). Draft chronicle of Fuping County (Fuping Xian Zhi Gao), Vols. 1, 4. (in Chinese).

Institute of Pucheng County. (1946). Draft chronicle of the Pucheng County (Pucheng Xian Zhi Gao), Vol. 2. (in Chinese).

Li, J. (813). Yuanhe Reign period general geography (Yuanhe Jun Xian Tu Zhi), Vol. 1. (in Chinese).

Li, T., \& Wang, X. (1905). New chronicle of Pucheng County (Pucheng Xian Xin Zhi), Vol. 1. (in Chinese).

Liu, D., \& Sun, P.-Y. (1584). Chronicle of Fuping County (Fuping Xian Zhi), Vols. 2, 8. (in Chinese).

Liu, Y., \& Shen, Q. (1735). General chronicle of Shaanxi Province (Shaanxi Tong Zhi), Vol. 9. (in Chinese).

Liu, X. (945). History of the Tang Dyansty (Jiu Tang Shu), Vol. 48. It is an official chronicle of the Tang Dynasty (618-907 A.D.). It totals 200 volumes. The compilation was carried out at imperial request. Beijing: Zhonghua Book Company (Zhonghua Shu Ju), 1975. (in Chinese).

Luo, T. (1296). Revised chronicle of Chang' an (Lei Bian Chang'an Zhi), Vol. 6. (in Chinese).

Qiao, L. (1740). Chronicle of Fuping County. Vol. 2. (in Chinese).

Song, M. (1076). Chronicle of Chang'an (Chang'an Zhi), Vol. 19. (in Chinese).

Song, Q., \& Ouyang, X. (1060). New history of the Tang Dyansty (Xin Tang Shu), Vol. 37. It is an official chronicle of the Tang Dynasty (618-907 A.D.). It totals 225 volumes. The compilation was carried out at imperial request. Beijing: Zhonghua Book Company, 1975. (in Chinese).

Wang, Q. (1013). Collection of material on the lives of emperors and ministers (Ce Fu Yuan Gui), Vol. 494. It totals 1,000 volumes. The compilation was carried out at imperial request. Beijing: Zhonghua Book Company, 1960. (in Chinese).

Wang, Y., \& He, F. (1714). Continued chronicle of Pucheng County (Pucheng Xian Xu Zhi). (in Chinese).

Wang, Z.-A. (1712). Continued chronicle of Chaoyi County (Chaoyi Xian Xu Zhi), Vol. 1. (in Chinese).

Wei, G. (1899). The Shaanxi Provincial Atlas (Shaanxi Quan Sheng Yu Di Tu). (in Chinese).

Wei, S. (554). History of the Northern Wei Dynasty (Wei Shu), Vol. 106. (in Chinese). 
Wu, L., \& Hu, W. (1778). Chronicle of Fuping County, Vol. 1. (in Chinese).

Zhang, T. (1739). The History of the Ming Dynasty (Ming Shi), Vol. 30 (in Chinese). History of the Ming Dynasty is the official history of the Ming Dynasty. (in Chinese).

Zhang, Y., Ma, P. (1625). Chronicle of Tongzhou prefecture (Tongzhou Zhi), Vol. 1. (in Chinese). Zhao, Y. (1701). Chronicle of Lintong County (Lintong Xian Zhi), Vol. 2. (in Chinese).

Zhu, X. (1906). Chronicle of the Chaoyi County (Chaoyi Xian Xiang Tu Zhi). (in Chinese).

Open Access This chapter is licensed under the terms of the Creative Commons Attribution 4.0 International License (http://creativecommons.org/licenses/by/4.0/), which permits use, sharing, adaptation, distribution and reproduction in any medium or format, as long as you give appropriate credit to the original author(s) and the source, provide a link to the Creative Commons license and indicate if changes were made.

The images or other third party material in this chapter are included in the chapter's Creative Commons license, unless indicated otherwise in a credit line to the material. If material is not included in the chapter's Creative Commons license and your intended use is not permitted by statutory regulation or exceeds the permitted use, you will need to obtain permission directly from the copyright holder. 